\title{
Viewpoint \\ Planning for food commons in the post-COVID world
}

\section{Introduction}

Food security - the availability of and access to food - is quickly becoming a major crisis within the COVID-Ig crisis. While food insecurity mounts, reports from across the world have detailed the destruction of food by producers en masse: animals euthanised, litres of milk poured down the drain, crops left to rot in the field. As some countries move to protectionist measures to secure their own food supply, we are warned that any impediments to global food trade could mean further catastrophe for millions of people.

In many ways the COVID-I9 crisis may feel like a sledgehammer that has dealt a shattering blow to the global food system. Yet the pandemic has merely laid bare the flaws of a system built on foundational vulnerabilities. It has always been contradictory to construct food security on distant just-in-time supply chains, controlled centrally by just a handful of multinational corporations, and heavily influenced by the whims of financial commodity markets. Already before the pandemic struck, our food systems were hanging on by a thread. A look around would reveal food insecurity in the midst of food waste, obesity in the midst of hunger, heavy dependence on fossil fuels in the face of climate change and peak oil, and a growing disconnection from nature in the face of soil degradation and ecosystem destruction.

In light of these widely acknowledged problems, which have intensified during the pandemic, we have reached a point where practically everyone is advocating a transition to sustainability (Swyngedouw, 2007). It is here that peasant farmers, national governments, supranational institutions and multinational corporations are seemingly in agreement: food systems need to become sustainable. However, what may appear on the surface to be a consensus is deeply split by two starkly contrasting visions of the future (Clapp, 2018). On the one hand is what we can call the techno-utopian vision. Mirroring the concept of 'narrow' ecological modernisation (Horlings and Marsden, 20II), the techno-utopians exhibit a hubristic faith in science and technology (that is, unscientific scientism) and continue a long tradition of seeking to simplify, standardise and control the complexities of nature and space from the top down (Shiva, 20i6).

Stephen Leitheiser is a Research Fellow, University of Groningen (RUG), Faculty of Spatial Sciences, Department of Spatial Planning and Environment, Landleven I, Groningen 9747AD, Netherlands; Lummina Geertuida Horlings is Professor of Socio-spatial Planning, University of Groningen (RUG), Faculty of Spatial Sciences, Department of Spatial Planning and Environment, Landleven I, Groningen 9700 AB, Netherlands; email: s.r.leitheiser@rug.nl; l.g.horlings@rug.nl 
On the other hand is what we can call the food-commons vision. This vision imagines a transition to diverse and place-specific food production, rooted in civic governance and shaped from the bottom up by the local conditions of culture, climate and ecology (Vivero-Pol et al., 20r9). This distinction is relevant, as both visions make substantive claims to sustainability, but identify different development pathways and unfold different notions of space and place. This raises questions such as, who will control and benefit from developments? What is the significance for policy makers? And what are the possibilities for a place-based approach to food production that supports community resilience?

In presenting an overview of these antagonistic visions, we aim to make a normative case for policy makers to facilitate a transition to the food commons. By highlighting examples from our engagement with civic food organisations, we argue that the 'seeds' of the food commons are already being planted all around us. However, these seeds of change must be acknowledged, made visible and nurtured so that they may grow and bloom.

\section{Techno-utopian sustainability}

The techno-utopian vision is rooted in the belief that further development of (centrally controlled) technologies will bring about a sustainable food future. With precision agriculture through digitalisation, and 'green' innovations through the miracles of science, it continues the trajectory of the industrial food system, which began its global ascendancy with the spread of Green Revolution in the ig6os. Since then, capital-intensive farming technologies - including chemical fertilisers and pesticides, hybrid seeds and fossil-fuelpowered machinery - have displaced subsistence food production around the world and enrolled human labour and appetites into global commodity markets. It is widely accepted that this trajectory must be altered in the face of new challenges, and the architects and benefactors of the global industrial food system have rushed to develop their own solutions. Although their prescriptions may appear different, they merely put a new coat of paint on current trajectories. Profit motives, driven by new investment frontiers, blind the techno-utopians to the hubristic risks inherent in their vision. For the techno-utopians, everything must change so that nothing has to change. In other words, radical revolutions to established ways of doing things - like producing food in a lab instead of a field, or using robots instead of workers to plant vegetables - are not only allowed, but required, to ensure that the structural relationships of centralised corporate control can remain intact. Ultimately, the assumptions of techno-utopians - that food production is inherently antagonistic to nature and that technology alone can solve our problems - increase the disconnection of food production from space and place, and conveniently ignore modes of production, distribution and consumption that do not align with (capitalist) economic interests. 
Digitalisation in agriculture refers to the use of information communication technologies (ICTs), big data and artificial intelligence (AI). Using drones and sensors to monitor local conditions, digitalisation is seen to enable 'precision agriculture' - a more efficient use of inputs, adapted to local conditions. Although digitalisation takes local geo-data conditions into account, these patented technologies remain centrally controlled by just a handful of multinational corporations (MNCs) with monopoly shares in global markets. Many farmers around the world are already dependent on MNCs for both agricultural inputs and access to commodity markets. This dependency has largely come about as a result of policies enforced by the World Trade Organisation's (WTO) structural-adjustment loans in recent decades. WTO policies have not only destroyed vibrant subsistence food economies; they have also actually worsened standards of living for local communities in many cases, and decreased their autonomy (Shiva, 2016). Top-down digitalisation would only continue these trends, as farmers would become more reliant on centrally controlled corporate products and expertise. Moreover, there are many reasons to scrutinise the techno-utopian promise of digital sustainability. For example, ICTs and AI have immense social and environmental impacts that are often overlooked. These include the many toxic environmental processes associated with the production of ICT and AI hardware (e.g. mining, energy consumption, waste disposal), and the toxic social processes that go into the acquisition of these materials (e.g. the child labour used to mine coltan in Congo). While digital technologies may indeed play some role in sustainable food systems, the techno-utopian insistence on using them as a 'silver bullet' is fool's gold.

A plethora of techno-utopian 'green' food innovations have also promised to bring about a sustainable food future. Several Silicon Valley-funded start-ups - including 'Beyond Meat' and 'Impossible Foods' - promise to innovate new plant-based replacement products that are healthier and more sustainable than their traditional counterparts produced through morally and environmentally harmful factory farming. However, as with digitalisation, proponents of these innovative food products fail to recognise the massive risks. In addition to the dangers of introducing radical novelty into human diets, these products are driven by yet another profit-making frontier that keeps the relationships of the dominant global food system mostly intact - dependent on centralised structures and energy-intensive processing and driven by short-term profits. For example, the 'plant-based' innovations incorporate a variety of cheap commodities from the global market, which are then centrally processed and sold with a significant profit margin that does not reward the producer and creates competition between farmers worldwide. 


\section{Food-commons sustainability}

Long before it was ever a commodity bought and sold on global markets, food was a common resource. Modern economics tells us that a resource can only be 'common' if it is not rivalrous (i.e. if I eat a carrot, you cannot eat it) or excludable (i.e. if you don't pay, I can easily prevent you from accessing the resource). Following this framework, many would assume that food economies should be privatised and enrolled into a market, or regulated by a command-and-control state. In other words, the power to make decisions about the production, distribution and consumption of food must be transferred from common people into a market system or a state bureaucracy. The common people, left to their own whims, would quite simply screw things up. While this narrative is powerful in modern culture, it is not historically accurate. The work of institutional economist Elinor Ostrom (I990), among others, has carefully documented thousands of instances in which communities have managed and governed their own common resources (for millennia) in ways that resemble neither states nor markets (cf. Brinkley, 2020). The various systems of resource management that Ostrom documented did not use the modern economist's logic of rivalry and excludability. Rather, they decided to manage resources in common quite simply because people in the community agreed to jointly cooperate in their care and management. In this way, the community itself is constituted by joint cooperation and participation. A look around shows that these types of commons have even been created all over within modern societies in which free trade and command-and-control governance are apparently ubiquitous.

Examples of the food commons include local community-supported agriculture (CSA), various value-based supply chains and new and nested production-consumption networks. What makes these systems of governance commons is that they go against, or beyond, the norms and rules set by established market systems and bureaucratic nation states. The vision of a food commons seeks to embed economic relations into society and the natural world, through utilising the various forms of ecologically available resources in sustainable ways. Communities are not subject to rules made elsewhere; they actively contribute in some way to decisions of economic governance. Quite often, these decisions are based on shared values like democracy, ecology, health, sustainability or supporting the local economy (Rosol, 2020). Crucially, as the food commons are rooted in a diversity of local conditions, and the sovereignty of the communities involved in the provision and distribution of the resource, they are much more resilient than their techno-utopian counterparts. Reports show that as the global food system has faltered, various food commons have flourished during the crisis. ${ }^{1}$

I See, for example, https://orfc.org.uk/how-community-food-providers-became-emergency-food-providers/ (accessed I4 August 2020); http://www.fao.org/in-action/food-for-cities\%2oprogramme/news/detail/en/c/I275II2 (accessed I4 August 2020). 


\section{Recognising the food commons and planning for them to grow}

We certainly do not have space here to detail all of the examples of the food commons flourishing around the world in the wake of the crisis. However, by acknowledging just a few groups that we are engaged with, we aim to call attention to the food commons as the basis for creating alternative food systems in the post-COVID world.

In Groningen, the Netherlands, where the authors reside, De Streekboer - an online marketplace with a mission to connect people to regional farmers who produce affordable and healthy food with respect for nature - has seen its customer base double and revenues quadruple since the beginning of the crisis. The peri-urban farm De Stadsakker, which sells bio-dynamic produce direct to consumers, has also had a significant increase in CSA customers since the beginning of the crisis. In order to help meet community needs in the event of supply-chain interruptions, De Stadsakker has also planned to double its produce yield. The urban garden Toentje produces fresh food for the food bank with the help of volunteers, providing access to affordable food for the urban poor (Ulug and Horlings, 20I9). These organisations have thrived as people have gained a new appreciation for supporting local businesses, and many volunteers have stepped up to help make these expansions possible.

Over in England, where the authors are engaged with civic food organisations, many groups associated with the Landworkers' Alliance (LWA), a union of small farmers united around the desire to create a food system rooted in social and environmental justice, have stepped up to help those in need during the pandemic. For example, the Granville Community Kitchen in London has helped some I50 people per day access healthy and nutritious food, including delivering cooked meals. Tamar Grow Local in Plymouth is one more example of a community cooperative enterprise that has not only been able to adapt to record-breaking demand during the crisis, but has continued to support needy families and soup kitchens with access to fresh and healthy foods.

While these various organisations have thrived during the crisis, they have not done so because of the support of established market and state institutions. They have done so despite them, and mostly because of the painstaking efforts (and often volunteer labour) of civic organisations and small businesses. Going forward, policy makers can work to facilitate and enable community-led food policies. Such policies should be place-based, and rooted in local knowledge, resources and capacities. Policy should focus on assisting the creation of closer links between cities and food-producing regions, for example by enabling access to land and finance for new entrant small farmers, and facilitating access to markets in cities. Urban access can come in the form of public procurement of local food (in canteens, schools, universities and hospitals), or the funding of community-led restaurants and logistical infrastructure (e.g. 
urban food hubs, pick-up points, delivery networks). Crucially, the approach to policy making should be decentralised and not defined in advance. Planting and tending to 'seeds' of the food commons can help to ensure a more resilient response to future crises.

\section{Acknowledgements}

The authors received funding from the RECOMS project within the European Union's Horizon 2020 Research and Innovation programme under the Marie SklodowskaCurie grant agreement No. $7653^{8}$.

\section{References}

BRINKLEY, C. (2020), 'Hardin's imagined tragedy is pig shit: a call for planning to recenter the commons', Planning Theory, 19, I27-44.

CLAPP, J. (2018), 'Mega-mergers on the menu: corporate concentration and the politics of sustainability in the global food system', Global Environmental Politics, 18, I2-33.

Hajer, M. (1995), The Politics of Environmental Discourse: Ecological Modernisation and the Policy Process, Oxford, Clarendon Press.

HORLINGS, L. G., and MARSDEN, T. K. (201 I), 'Towards the real green revolution? Exploring the conceptual dimensions of a new ecological modernisation of agriculture that could "feed the world", Global Environmental Change, 21, 44 ${ }^{\mathrm{I}}{ }^{2}$.

Ostrom, E. (1990), Governing the Commons, Cambridge, Cambridge University Press.

ROSOL, M. (2020), 'On the significance of alternative economic practices: reconceptualizing alterity in alternative food networks', Economic Geography, 96, 52-76.

SHIVA, V. (2016), Who Really Feeds the World? The Failures of Agribusiness and the Promise of Agroecology, Berkeley, North Atlantic Books.

SWYNGEDOUW, E. (2007), 'Impossible "sustainability" and the postpolitical condition', in R. Krueger and D. Gibbs (eds), The Sustainable Development Paradox: Urban Political Economy in the United States and Europe, New York, Guilford Press, I3-40.

ULUG, G. and HORLINGS, L. G. (2019), 'Connecting resourcefulness and social innovation: exploring conditions and processes in community gardens in the Netherlands', Local Environment, 24, I47-66.

VIVERO-POL, J. L., FERRANDO, T. and DE SCHUTTER, O. (eds) (20I9), Routledge Handbook of Food as a Commons, New York, Routledge. 